\title{
INFLUÊNCIA DO SOLO NO TEMPO E COMPORTAMENTO DAS ROTAÇÕES UTILIZADAS NOS PREPAROS PRIMÁRIO E SECUNDÁRIO
}

\section{SOIL INFLUENCE IN THE TIME AND BEHAVIOR OF THE ROTATIONS USED IN PRIMARY AND SECONDARY PREPARATIONS}

\author{
Matheus Dias Santos ${ }^{1}$; Geovana Brito Queiroz ${ }^{2}$; Gabriela Leite Silva ${ }^{3}$; Ingrid Thalia Prado de \\ Castro $^{4}$; Doalcey Rocha Chagas ${ }^{5}$
}

DOI: https://doi.org/10.31692/978-65-991061-7-0.306-311

\section{INTRODUÇÃOO}

A partir da década de 60, o Brasil passou por intensa transformação agrícola, isso se deu em decorrência do processo de modernização da agricultura sendo o trator considerado o eixo dessa transformação. $\mathrm{O}$ uso do trator agrícola associado à máquinas e implementos levou à diminuição do desgaste de trabalhadores, tornando-se responsável, também, por significativo aumento da capacidade de produção agrícola (VALE et al., 2011).

Mesmo com esses avanços, de acordo com Linhares et al., (2012) é necessário "a realização de estudos que visem a conhecer a capacidade produtiva e as possíveis variáveis que interferem no rendimento de máquinas e equipamentos", pois, com isso, torna-se possível o desenvolvimento de técnicas para melhorarem o desempenho operacional e a eficiência das máquinas, maximizando a produtividade e reduzindo os custos de produção.

No Brasil, utilizam-se dados contidos em trabalhos de vários autores, normalmente retirados dos padrões da American Society of Agricultural Engineers (ASAE) e, apesar de útil, essa situação mostra que a necessidade desses estudos torna-se ainda maior, pois o Brasil praticamente não dispõe de diversos desses parâmetros necessários para averiguação da eficiência de campo para máquinas ou conjuntos normalmente empregados, e sem estes tornase quase impossível a execução de cálculos confiáveis (PACHECO, 2000).

Diante do exposto, o presente trabalho tem por objetivo observar o comportamento de um trator nas operações de preparo primário e secundário de solo por meio da analise do desempenho do mesmo em 4 rotações e do tempo gasto na realização dos procedimentos.

\footnotetext{
1 Graduando (a) do Curso de Engenharia Agronômica, UESB, Vitória da Conquista, BA, Brasil. matheusdiassantos2013@gmail.com

2 Graduando (a) do Curso de Engenharia Agronômica, UESB, Vitória da Conquista, BA, Brasil. geovanabritoq@hotmail.com

3 Graduando (a) do Curso de Engenharia Agronômica, UESB, Vitória da Conquista, BA, Brasil. gabriela.leitesilva@hotmail.com

4 Graduando (a) do Curso de Engenharia Agronômica, UESB, Vitória da Conquista, BA, Brasil. giycastro@gmail.com

${ }^{5}$ Departamento de Engenharia Agrícola e Solos, UESB, Vitória da Conquista, BA, Brasil. doalcey@uesb.edu.br
} 


\section{FUNDAMENTAÇÃO TEÓRICA}

Os tratores, em conjunto com máquinas e implementos, por meio de seu trabalho, são empregues nas mais diversas funções (VALE et al., 2011). Entre essas, está o preparo do solo.

O preparo do solo consiste em operações que tem como finalidade proporcionar condições favoráveis para o desenvolvimento adequado das culturas (CARVALHO FILHO et al., 2007; FURLANI, LOPES \& SILVA, 2005); é classificado em preparo inicial (caracterizado por operações como de desmatamento) ou em preparo periódico, quando a área já é utilizada e se caracteriza por operações de movimentação do solo com a finalidade de instalação periódica de culturas (BALASTREIRE, 1990).

De acordo com Carvalho Filho et al., (2007) o preparo periódico pode ser dividido em preparo primário e preparo secundário. O primeiro caracteriza-se por operações mais profundas e grosseiras (aração e/ou escarificação) e que têm como objetivo o revolvimento do solo e o segundo pode ser definido como todas as operações superficiais realizadas após o preparo primário (destorroamento e nivelamento, atividades como gradagens em geral) e que visam produzir ambiente favorável ao desenvolvimento inicial da cultura (CARVALHO FILHO et al., 2007).

Apesar de terem surgido modernas técnicas de semeadura direta que têm demonstrado, para determinadas condições de solo, clima e culturas, obter produtividade tão boa ou até superior que com métodos tradicionais de semeadura e plantio, o preparo convencional do solo continuará a ser feito para culturas ou condições em que não existe a possibilidade de utilização de técnicas de semeadura direta (BALASTREIRE, 1990).

De acordo com Pacheco (2000), para uma boa eficiência no preparo de solo, diversos fatores devem ser conhecidos e considerados, pois envolvem aspectos desde o planejamento (escolha dos equipamentos, por exemplo) até a execução do trabalho e, consequentemente, custos envolvidos, entre estes fatores estão o tempo de realização das atividades e o tipo de solo e suas condições e implicações.

\section{METODOLOGIA}

O experimento foi conduzido na Universidade Estadual do Sudoeste da Bahia, campus de Vitória da Conquista, BA. A localização geográfica está definida pelas coordenadas: latitude de $14^{\circ} 51^{\prime} 58^{\prime \prime}$ S e longitude de 4050'22”'W, sendo a altitude média de $923 \mathrm{~mm}$; clima tipo tropical de altitude (Cwa) de acordo com Köppen e precipitação média anual de $717 \mathrm{~mm}$ (SEI, 2013). O solo foi classificado como Gleissolo Franco-Argiloso apresentando umidade média de $15 \%$. 
Foi utilizado um trator agrícola, marca New Holland, modelo TL 95E, 4x2 com tração dianteira auxiliar acionada, potência máxima no motor de 73,6 kW (100 cv) a $2400 \mathrm{rpm}$ devidamente lastrado para trabalhar em condições normais. Possui um torque máximo a 1400 rpm de $380 \mathrm{Nm}$. Foi realizada uma seleção das marchas utilizadas para que as velocidades de aração e gradagem ficassem dentro do intervalo adequado às operações. Desta forma, utilizou-se a Gama 2 do grupo de marchas reduzidas com a $2^{\mathrm{a}}$ marcha do grupo de velocidade do modelo, correspondentes às velocidades em campo de 4,0-6,0 $\mathrm{km} \mathrm{h}^{-1}$.

Utilizou-se uma grade de discos aradora marca Piccin, modelo GACR, com 12 discos totais, com discos de 26 polegadas e um arado de 4 discos da marca Baldan modelo ARH (L) com discos de 28 polegadas. Regulou-se a grade aradora para trabalhar à profundidade de 25 $\mathrm{cm}$ e o arado para trabalhar à profundidade de $40 \mathrm{~cm}$.

O delineamento experimental utilizado foi o inteiramente casualizado (DIC), em esquema fatorial (dois implementos - arado de disco e grade aradora e quatro rotações: 1400, 1700, 2000 e $2300 \mathrm{rpm}$ ) com quatro repetições, totalizando 32 parcelas de $40 \mathrm{~m}$ de comprimento cada uma. Deixou-se uma área de bordadura para realização de manobras e de 5 $\mathrm{m}$ do início de cada parcela para início da operação. As variações da rotação durante a operação foram averiguadas visualmente pelo operador da máquina e posteriormente anotadas e o tempo de trabalho na parcela marcado em cronometro.

Os resultados foram submetidos à análise de variância e os contrastes entre as médias que diferiram entre si, pelo teste F, foram comparados pelo Teste de Tukey em nível de 5\% de significância; os dados obtidos para as rotações e para tempo foram submetidos à análise de regressão polinomial pelo programa Sisvar versão 5.6.

\section{RESULTADOS E DISCUSSÕES}

Observa-se na Tabela 1 que tanto a média das rotações quanto a média dos tempos para o arado foram maiores que para a grade aradora, tal diferença pode ser explicada pelo fato do preparo primário ter desfeito a estrutura do solo facilitando a ação da grade aradora. Os valores obtidos para o arado são decorrentes da maior resistência do solo a penetração o que consequentemente leva à queda na rotação e redução do deslocamento do trator com o implemento na área elevando o tempo para completar o trabalho.

Dessa forma, após o preparo primário, com a quebra da resistência do solo, houve menor redução da rotação para a grade aradora e essa também conseguiu desenvolver o trabalho em menor tempo por ter seu deslocamento facilitado na área. Trabalho realizado por Vale et al., (2011) corrobora com essa afirmação, pois explicam que alterações por eles 
observadas nas rotações do motor do trator seriam decorrentes das variações nas condições de topografia do terreno e pela densidade da vegetação dentro da área, demandando valores de potência diferentes. Com isso no caso do trabalho aqui desenvolvido o responsável por essas alterações foram as condições do solo.

Tabela 1: Médias da rotação efetiva (rpm) desenvolvida pelo trator e do tempo (em segundos) gasto nas operações de preparo primário realizado com o arado e secundário com a grade aradora. Fonte: Própria.

\begin{tabular}{ccc}
\hline Tratamentos & Rotação efetiva (rpm) & Tempo (s) \\
\hline Grade aradora & $1668,75 \mathrm{~b}$ & $39,6875 \mathrm{~b}$ \\
Arado & $1743,75 \mathrm{a}$ & $50,3125 \mathrm{a}$ \\
\hline CV $(\%)$ & 3,05 & 11,56 \\
\hline
\end{tabular}

Médias seguidas por letras iguais na coluna não diferem entre si pelo teste Tuey (P>0,05). CV: Coeficiente de variação

Como citado, trabalhou-se em solo do tipo gleissolo e segundo Barbosa (2006) os gleissolos são solos minerais, hidromórficos, apresentando horizontes A (mineral) ou $\mathrm{H}$ (orgânico), seguido de um horizonte de cor cinzento-olivácea, esverdeado ou azulado, chamado horizonte glei, resultado de modificações sofridas pelos óxidos de ferro existentes no solo (redução) em condições de encharcamento durante o ano todo ou parte dele. $\mathrm{O}$ horizonte glei pode começar a $40 \mathrm{~cm}$ da superfície. São solos mal drenados, podendo apresentar textura bastante variável ao longo do perfil.

Observando apenas a textura, estes solos ao longo do perfil quando apresentam muita argila na subsuperfície podem apresentar sérios problemas, principalmente quando drenados. À medida que esses solos secam, ficam endurecidos, prejudicando o desenvolvimento de raízes e o manejo do preparo (OLIVEIRA, 2017). No caso do gleissolo, as características de grande coesão provocadas pelo acumulo de argila exigem maior esforço da máquina para que realize o trabalho da forma desejada.

A Figura 1 mostra o comportamento da rotação efetiva (1-A) e do tempo gasto (1-B) em relação às rotações estabelecidas para o trator. Nota-se que a média dos dados referentes à rotação efetiva ficaram abaixo da rotação planejada, mas apresentam comportamento crescente; no que se refere ao tempo, constata-se que com o aumento da rotação o conjunto trator implemento desenvolveu o trabalho em tempo menor. Essas observações evidenciam a influência da característica coesa do gleissolo e a necessidade de uma maior rotação efetiva aplicada para chegar na planejada e se reduzir o tempo de operação. 
Figura 1: Comportamento da rotação efetiva (1-A) e do tempo gasto (em segundos) (1-B) em relação às rotações estabelecidas no trator. Fonte: Própria.

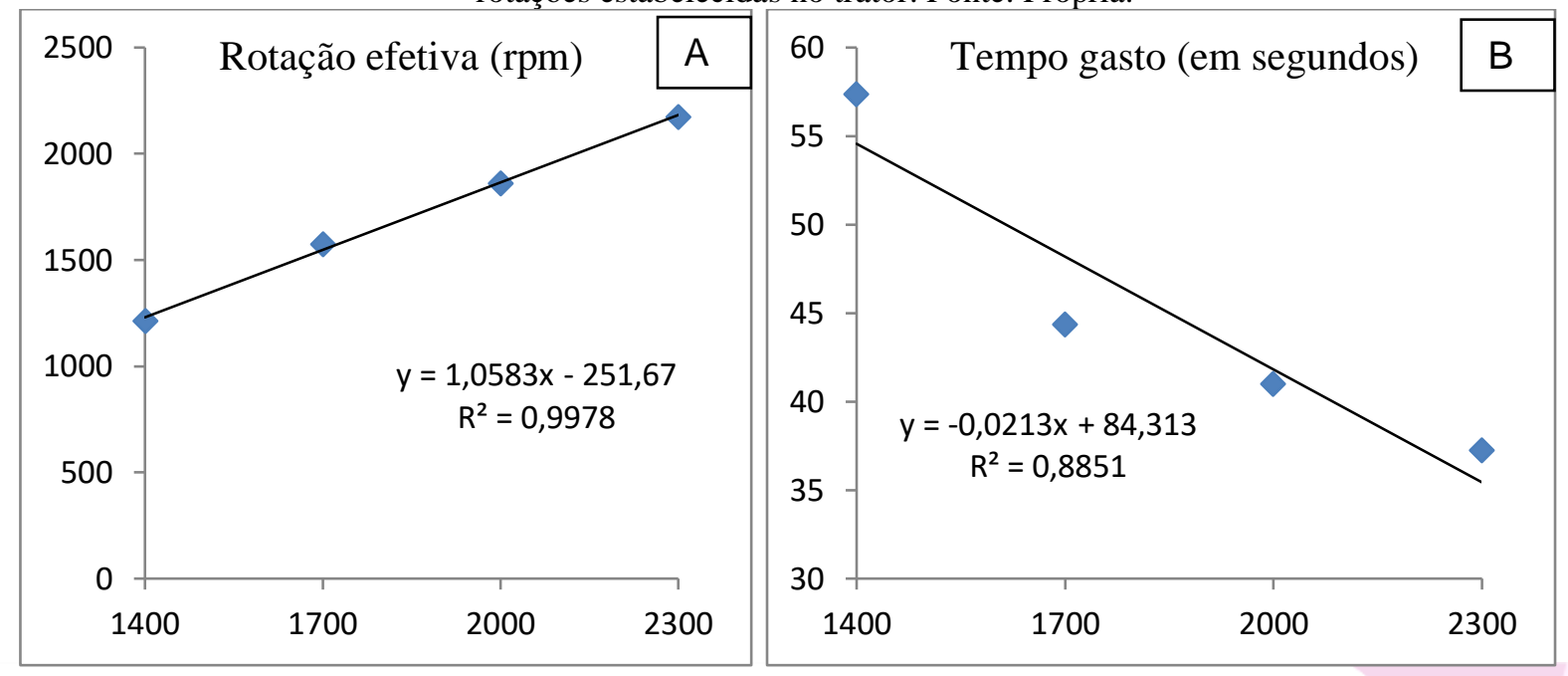

A observação aqui realizada de que o aumento da rotação diminui o tempo gasto para realização de um trabalho é mencionada por Almeida et al., (2010) onde aponta que para aumentar a velocidade de deslocamento em pequenas proporções, normalmente o operador eleva a rotação de trabalho, aponta também que essa ação leva à redução do torque do motor e aumento no consumo de combustível o que é contrário ao afirmado por Vale et al., (2011) que relata redução do consumo com aumento da rotação. Apesar de, aqui, não se tratar da velocidade conforme procedimento utilizado por Montanha et al., (2011) é possível obtê-la e como percebe-se reduzindo-se esse tempo ocorre o aumento da velocidade. Dessa forma, aqui nota-se que a redução do tempo observado implica em aumento de velocidade e de acordo com Duarte Jr et al., (2008) maiores velocidades de realização de trabalho proporcionam maior capacidade de campo efetiva.

\section{CONCLUSÕES}

As rotações e o tempo de realização dos procedimentos foram afetadas pela condição do solo. As rotações observadas ficaram abaixo do planejado. O aumento da rotação levou à redução no tempo para realização da operação.

\section{REFERÊNCIAS}

BALASTREIRE, L.A. Máquinas agrícolas. São Paulo: Manole, 1990. 307p.

BARBOSA, L. M. Manual para recuperação de áreas degradadas do estado de são paulo: Matas Ciliares do Interior Paulista. São Paulo: Instituto de Botânica, 2006.

CARVAlHO FILHO, A.; SILVA, R. P. DA.; CENTURION, J. F.; CARVALHO, L. C. C.; LOPES, A. Agregação de um latossolo vermelho submetido a cinco sistemas de preparo do 
solo em Uberaba - MG. Eng. Agríc., Jaboticabal, v.27, n.1, p.317-325, jan./abr. 2007.

DUARTE JÚNIOR, J. B.; GARCIA, R. F.; COELHO, F. C.; AMIM, R T. Desempenho de trator-implemento na cana-de-açúcar em sistemas de plantio direto e convencional. Revista Brasileira de Engenharia Agrícola e Ambiental, Campina Grande, PB, v.12, n.6, p.653658, 2008.

FURLANI, C. E. A.; LOPES, A.; SILVA, R. P. DA. Avaliação de semeadora-adubadora de precisão trabalhando em três sistemas de preparo do solo. Eng. Agríc., Jaboticabal, v.25, n.2, p.458-464, maio/ago. 2005.

LINHARES, M.; SETTE JÚNIOR, C. R.; CAMPOS, F.; YAMAJI, F. M. Eficiência e desempenho operacional de máquinas harvester e forwarder na colheita florestal. Pesq. Agropec. Trop., Goiânia, v. 42, n. 2, p. 212-219, abr./jun. 2012.

MONTANHA, G. K.; GUERRA, S. P. S.; ANDRADE-SANCHEZ, P.; CAMPOS, F. H.; LANÇAS, K. P. Consumo de combustível de um trator agrícola no preparo do solo para a cultura do algodão irrigado em função da pressão de inflação nos pneus. Revista Energia na Agricultura. Botucatu, vol. 26, n.1, 2011, p.39-51.

OLIVEIRA, S. G. DE. Propriedades físico-hídricas de um gleissolo háplico sob três diferentes cultivos. [Trabalho de conclusão de curso apresentado ao Instituto Federal de Minas Gerais - Campus São João Evangelista como exigência parcial para obtenção do título de Bacharel em Agronomia]. São João Evangelista, Minas Gerais. 2017.

PACHECO, E. P. Seleção e custo operacional de máquinas agrícolas. Rio Branco: Embrapa Acre, 2000. 21p. (Embrapa Acre. Documentos, 58)..

SEI. Superintendência de Estudos Econômicos e Sociais da Bahia. Estatística dos municípios Baianos. v. 4, 450p., 2013. Disponível em: << http://www.sei.ba.gov.br/images/publicacoes/sumario/estatisticas_municipios/sumario_est_m un_2011_v20.pdf > >. Acessado em: 22 set. 2018.

VALE, W. G. do.; GARCIA, R. F.; CORRÊA JUNIOR, D.; GRAVINA, G. A.; SOUZA, E. F. Desempenho operacional e energético de um trator agrícola durante a operação de roçagem. Gl. Sci. Technol., v.4, n.2, p.68-75, mai/ago. 2011. 